\title{
Successful management of cerebral embolism during TAVR
}

\author{
Christian Thilo $\cdot$ Christoph J. Maurer • \\ Ansgar Berlis • Wolfgang von Scheidt • \\ Albert M. Kasel
}

Sirs:

sufficient collateralization (Fig. 1a). Contrast injection via

An 89-year-old woman underwent transfemoral aortic valve replacement (TAVR) for treatment of severe symptomatic aortic stenosis as recommended by the institutional heart team (transvalvular gradient $\max 71 \mathrm{mmHg} / \mathrm{mean}$ $55 \mathrm{mmHg}$ ). Aortic annulus size as determined by computed tomography (CT) was $19 \mathrm{~mm}$ with moderate calcifications. Accordingly, a $23 \mathrm{~mm}$ Edwards Sapien $\mathrm{XT}^{\mathrm{TM}}$ valve (Edwards Lifesciences) was selected.

The patient was preloaded with $500 \mathrm{mg}$ Aspirin ${ }^{\mathrm{TM}}$ and $100 \mathrm{IE} / \mathrm{kg}$ of unfractionated heparin was given during the procedure. After successful implantation of the valve under conscious sedation, the patient presented with right sided hemiplegia and aphasia. The patient was immediately transferred from the cath lab to cerebral CT angiography which revealed complete occlusion of the M1 branch of the left middle cerebral artery (ACM). After transfer to the neuroradiology intervention room, intubation, and reaccess to the left femoral artery, a catheter was placed in the left carotid artery confirming the occlusion and

a microcatheter after passage of the occlusion with a microwire demonstrated correct positioning (Fig. 1b). Subsequently, a Solitaire ${ }^{\mathrm{TM}} 4 \times 20 \mathrm{~mm}$ Stent Retriever (Covidien) was placed in the occluded segment and released for $5 \mathrm{~min}$. Contrast injection assessed filling of the stent retriever (Fig. 2a). Subsequently, the device was retrieved and substantial thrombotic material was attained (Fig. 3). The final angiogram revealed complete restoration of flow (Fig. 2b). The patient was extubated after the procedure and mobilized on the next day without any residual neurological pathology.

Cerebral embolization is a critical complication of TAVR [1]. Successful neurovascular rescue was recently described in a patient with stroke after TAVR performed in general anesthesia [2]. Conduction of TAVR under conscious sedation, however, allows for rapid assessment of neurological symptoms during and after the procedure. Timely diagnosis of cerebral ischemia facilitates immediate and full restoration of cerebral flow.

C. Thilo $(\bowtie) \cdot$ W. von Scheidt · A. M. Kasel

I. Medizinische Klinik, Klinikum Augsburg, Herzzentrum

Augsburg-Schwaben, Stenglinstr. 2, 86156 Augsburg, Germany

e-mail: christian.thilo@klinikum-augsburg.de

C. J. Maurer · A. Berlis

Klinik für Diagnostische Radiologie und Neuroradiologie, Klinikum Augsburg, Stenglinstr. 2, 86156 Augsburg, Germany

A. M. Kasel

Deutsches Herzzentrum, Technische Universität, Lazarettstr. 36, 80636 Munich, Germany 
Fig. 1 a Selective cerebral angiogram confirming the total occlusion of the left middle cerebral artery (arrow). b After passing of the occlusion with a microwire, contrast administration via a microcatheter (arrow) demonstrates correct positioning

Fig. 2 a Selective cerebral angiogram with stent deployed in the left middle cerebral artery (ACM, arrow indicates distal stent end). $\mathbf{b}$ Total restoration of flow within the ACM (arrow)
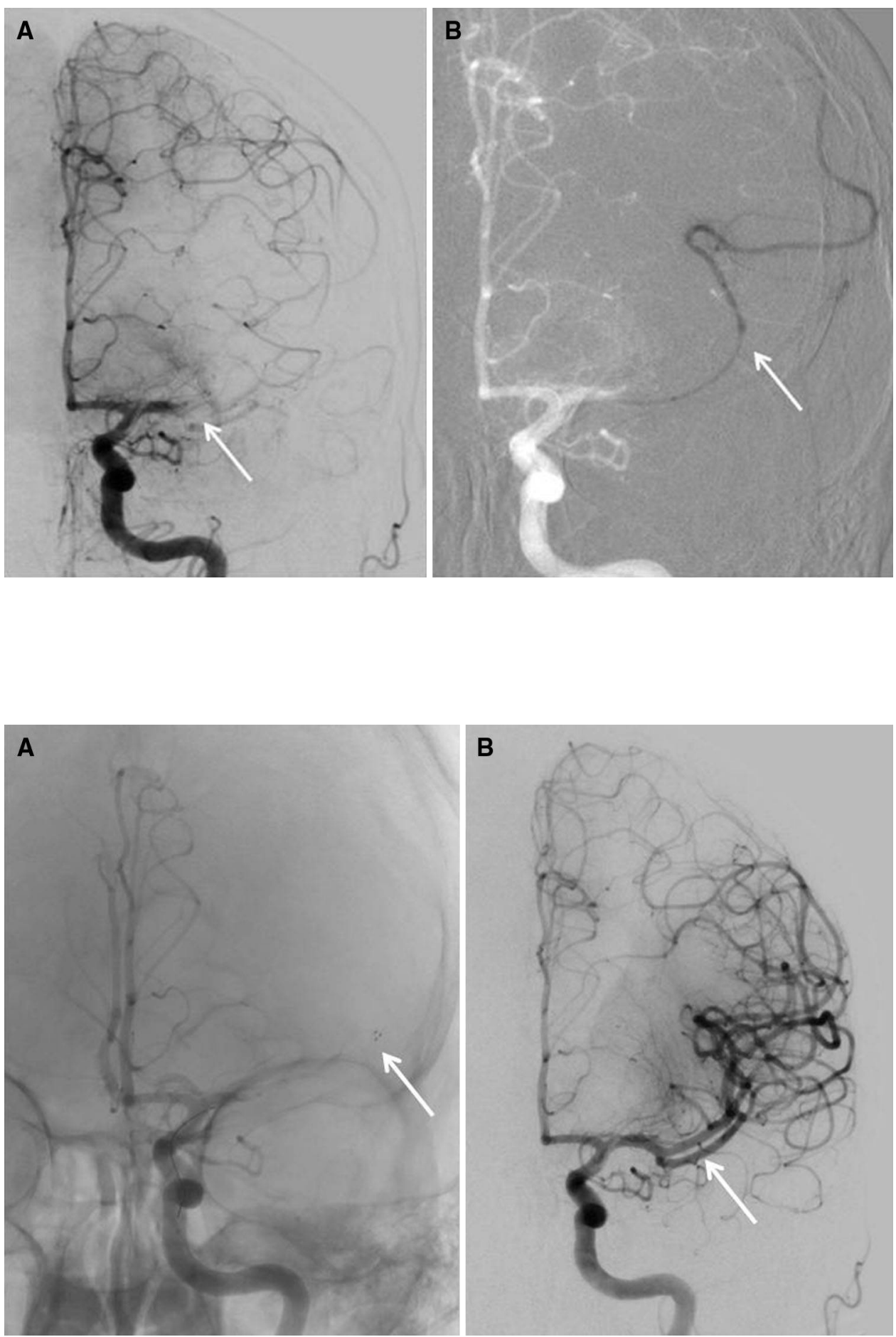


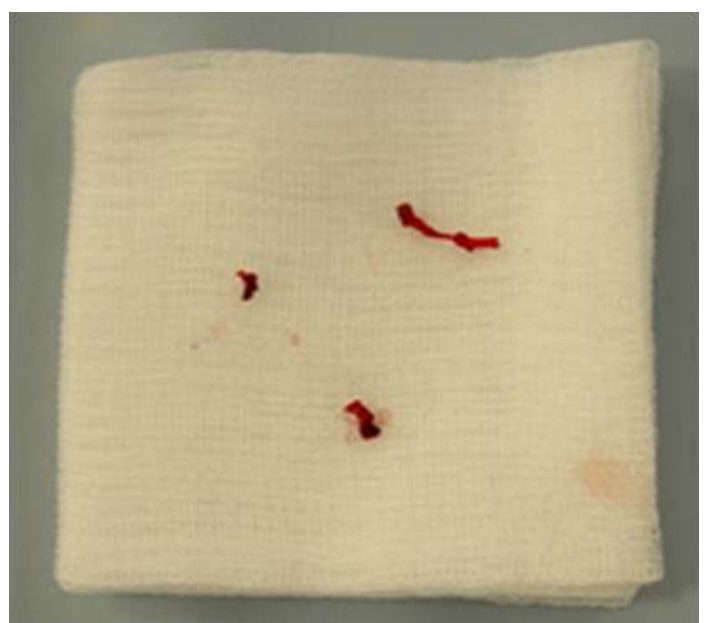

Conflict of interest AMK is a medical consultant for and receives research support from Edwards Sapien Valves (Edwards Life Sciences). The other authors have no conflict of interest to disclose.

\section{References}

1. Stortecky S, Windecker S, Pilgrim T, Heg D, Buellesfeld L, Khattab AA, Huber C, Gloekler S, Nietlispach F, Mattle H, Jüni P, Wenaweser P (2012) Cerebrovascular accidents complicating transcatheter aortic valve implantation: frequency, timing and impact on outcomes. EuroIntervention 8:62-70

2. Salinas P, Moreno R, Frutos R, Lopez-Sendon JL (2013) Neurovascular rescue for thrombus-related embolic stroke during transcatheter aortic valve implantation. JACC Cardiovasc Interv 6:981-982

Fig. 3 Retrieved thrombi from the middle cerebral artery 